\title{
Hypoxia is regulating enzymatic wood decomposition and intracellular carbohydrate metabolism in filamentous white rot fungus
}

\author{
Hans Kristian Mattila ${ }^{*^{*}}$ (D), Mari Mäkinen ${ }^{1,2}$ and Taina Lundell ${ }^{1}$
}

\begin{abstract}
Background: Fungal decomposition of wood is considered as a strictly aerobic process. However, recent findings on wood-decaying fungi to produce ethanol from various lignocelluloses under oxygen-depleted conditions lead us to question this. We designed gene expression study of the white rot fungus Phlebia radiata (isolate FBCC0043) by adopting comparative transcriptomics and functional genomics on solid lignocellulose substrates under varying cultivation atmospheric conditions.

Results: Switch to fermentative conditions was a major regulator for intracellular metabolism and extracellular enzymatic degradation of wood polysaccharides. Changes in the expression profiles of CAZy (carbohydrate-active enzyme) encoding genes upon oxygen depletion, lead into an alternative wood decomposition strategy. Surprisingly, we noticed higher cellulolytic activity under fermentative conditions in comparison to aerobic cultivation. In addition, our results manifest how oxygen depletion affects over 200 genes of fungal primary metabolism including several transcription factors. We present new functions for acetate generating phosphoketolase pathway and its potential regulator, Adr1 transcription factor, in carbon catabolism under oxygen depletion.
\end{abstract}

Conclusions: Physiologically resilient wood-decomposing Basidiomycota species P. radiata is capable of thriving under respirative and fermentative conditions utilizing only untreated lignocellulose as carbon source. Hypoxiaresponse mechanism in the fungus is, however, divergent from the regulation described for Ascomycota fermenting yeasts or animal-pathogenic species of Basidiomycota.

Keywords: Phlebia radiata, Basidiomycota, Hypoxia, Lignocellulose, Biodegradation, Fungal metabolism, Gene expression, Bioethanol, Transcription factor, Carbohydrate-active enzymes

\section{Background}

Decomposition leading to utilization of plant biomass lignocelluloses by filamentous Ascomycota and Basidiomycota fungi is regarded as an aerobic process, since fungal respirative metabolism requires oxygen. Specifically oxygen is required to gain ATP for cellular metabolism and hyphal growth, as well as for active expression and

*Correspondence: hans.mattila@helsinki.fi

1 Department of Microbiology, Faculty of Agriculture and Forestry, Viikki Campus, University of Helsinki, 00014 Helsinki, Finland

Full list of author information is available at the end of the article secretion of an array of enzymes and metabolites necessary for the decomposition of plant cell wall biopolymers (cellulose, hemicelluloses, pectin, lignin) [1-3]. Furthermore, wood-decomposing fungi generate an oxidative first phase of early decay upon hyphal colonization of their solid lignocellulose habitat. This process generates reactive oxygen species (ROS) and produces specific extracellular redox enzymes against lignocellulose components [4-6]. In white rot fungi, enzymatic attack on wood lignin and crystalline cellulose microfibrils require specific redox enzymes dependent on molecular oxygen or ROS initiators like hydrogen peroxide $[2,4,7]$.

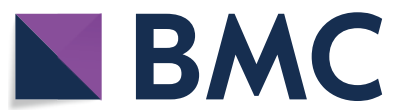

c) The Author(s) 2020. This article is licensed under a Creative Commons Attribution 4.0 International License, which permits use, sharing, adaptation, distribution and reproduction in any medium or format, as long as you give appropriate credit to the original author(s) and the source, provide a link to the Creative Commons licence, and indicate if changes were made. The images or other third party material in this article are included in the article's Creative Commons licence, unless indicated otherwise in a credit line to the material. If material is not included in the article's Creative Commons licence and your intended use is not permitted by statutory regulation or exceeds the permitted use, you will need to obtain permission directly from the copyright holder. To view a copy of this licence, visit http://creativeco mmons.org/licenses/by/4.0/. The Creative Commons Public Domain Dedication waiver (http://creativecommons.org/publicdomain/ zero/1.0/) applies to the data made available in this article, unless otherwise stated in a credit line to the data. 
Basidiomycota fungi are the main inhabitants and decomposers of dead wood and wood debris in the boreal and temperate forests ecosystems, and these fungi are responsible for generating either white or brown rot in wood $[8,9]$. Brown rot decay may occur in construction wood [10] and in standing tree trunks in the forests, while white rot decay is more common in fallen trunks and wood subjected to moist soil conditions [2, 7, 9]. Wood-decaying saprobic fungi elongate their hyphae inside dead wood, and the fungi may confront rain, or flooding in fallen waterlogged trunks. White rot may be encountered even in saline coastal areas such as mangrove forests [11].

Therefore, we hypothesized that under the wet conditions of their natural habitats, the fungal hyphae may encounter situations of limited oxygen availability. It is thus likely that these organisms temporarily tolerate microaerophilic to anaerobic growth environments by switching to fermentative metabolism while they decompose wood. In fungi, production of ethanol by sugar fermentation is apparently a conserved trait that is not restricted to only the Ascomycota yeasts like Saccharomyces cerevisiae [12, 13].

As an example of this metabolic ability among wooddecaying fungi, white rot species of the taxonomic order Polyporales, genus Phlebia have shown great potential for ethanol fermentation from untreated lignocellulose $[11,14-16]$. The phlebioid fungi are able to decompose both the wood carbohydrates and lignin moieties via secretion of a wide array of carbohydrate-active enzymes (CAZy [17] http://www.cazy.org/) and lignin-modifying oxidoreductases $[4,18]$. However, apart from their ethanol fermentation ability little is known about the actual processes and regulation of the fermentative and primary metabolism of the white rot fungi.

Our previous proteomic and transcriptomic study of the phlebioid species $P$. radiata indicated time-dependent expression and the potential for co-regulation of several CAZy encoding genes [19]. In this study, we aimed to explore overall gene expression as well as regulation of the fungal metabolism under fermentative and ethanolproducing growth conditions.

We discovered that both enzymatic decomposition of wood lignocellulose and subsequent accumulation of extracellular ethanol occur under hypoxic conditions. These findings offer biological explanations for how variable environmental conditions affect the decomposition of wood lignocellulose and plant biomasses. Moreover, specific connections between genetic regulation of fungal extracellular and intracellular metabolism may be emphasized upon oxygen depletion. We also present a unique fungal metabolic pathway for adaptation to hypoxia.

\section{Results}

Extracellular decomposition of lignocellulose upon oxygen depletion

The role of lignocellulose and oxygen depletion was studied by analyzing in total 14 transcriptomes of $P$. radiata, derived from five different cultivation conditions. The RNA-Seq data were deposited to Gene Expression Omnibus [20] and is accessible through GEO accession number GSE141153 https://www.ncbi.nlm.nih.gov/geo/query/ acc.cgi?acc $=$ GSE141153. The 14 cultivations were named as Malt extract 1-3; Spruce 2 weeks 1 and 3; Spruce 4 Weeks 1-3 [4] followed by Spruce + board aerobic 1-3; and Spruce + board anaerobic_1-3 (this study). "Spruce 2 and 4 weeks" accompanied with "Spruce + board aerobic" represent lignocellulose containing cultivations with normal atmosphere. "Spruce + board anaerobic" is identical to "Spruce+board aerobic" except for the cultivation atmosphere. Fermentative conditions were created by sealing vials of "Spruce + board anaerobic" with rubber plugs. "Malt extract" is a liquid cultivation with no lignocellulose substrate.

Gas contents of the atmospheres of "Spruce + board aerobic" and "Spruce+board anaerobic" were measured over time during the cultivation. Cultivation flasks of "Spruce+ board anaerobic" that were sealed with impermeable rubber plugs contained only $1.1( \pm 0.2) \%$ $(\mathrm{v} / \mathrm{v})$ of oxygen $\left(\mathrm{O}_{2}\right)$ after 7 days of incubation. Oxygen content was found to be stabile similar in following time points day 14, 21 and 49. As expected the atmosphere of "Spruce + board aerobic" cultivation had approximately $21 \%(\mathrm{v} / \mathrm{v})$ of oxygen throughout the cultivation (Additional file 1: Table S1).

Based on hierarchical clustering of VST normalized values of these transcriptomes, we found that expression of all the 12,017 differentially expressed genes formed two major groups (Fig. 1a). Fermentative conditions on lignocellulose ("Spruce + board anaerobic 1-3", this study) and in the stationary liquid malt extract cultures (Malt extract 1-3) [4] formed two distantly related groups while aerobic conditions on lignocellulose substrates ("Spruce + board aerobic", this study; Spruce 2 weeks and 4 weeks) [4] formed one main gene expression group. The CAZy encoding genes clustered according to cultivation atmosphere or growth substrate similar to all 12,017 differently expressed genes were analyzed (Fig. 1a, b). The 215 selected core metabolic genes clustered into a different pattern: ethanol-producing anaerobic conditions on lignocellulose substrate formed a separate main cluster (Fig. 1c). In all cases, individual transcriptomes of the biological replicates were the most similar to each other (Fig. 1, top panels).

Clustering analysis was resumed by dividing the 12,017 differentially expressed genes into 50 clusters by the 

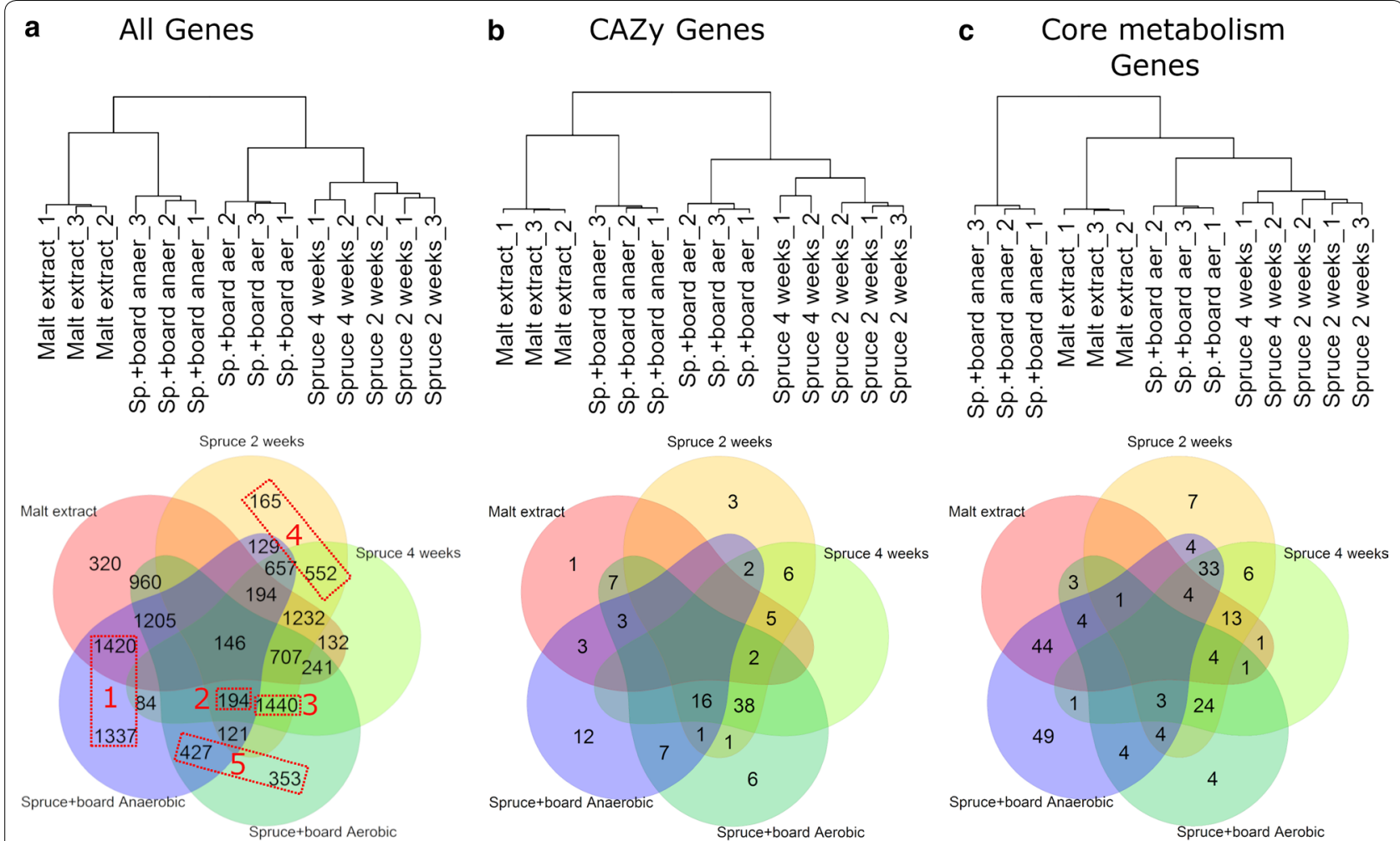

Fig. 1 Clustering of $P$. radiata transcriptomes. Top: hierarchical clustering of all 14 transcriptomes. Sp., spruce; anaer, anaerobic; aer, aerobic. Below: Venn representation of upregulation patterns in relation to the growth substrate. a Clustering based on the expression of 12,017 differentially expressed genes. b All 113 CAZy genes. c All 216 Core metabolism genes. Biological explanation for the boxed Groups 1-5 (in red) in a is provided in the main text

Mfuzz analysis (Additional file 1: Table S2). The Mfuzz C (center) value [21] from each culture condition was examined for the $50 \mathrm{Mfuzz}$ clusters. The C-values were used to indicate which genes were induced (higher expression of transcripts) or repressed (lower expression of transcripts) under a specific cultivation condition atmosphere or substrate in relation to other cultivation conditions and substrates (induced: $C$ value $>0$; repressed: $C$ value $<0$ ) (Additional file 1: Tables S2 and S3). Mfuzz cluster number 47 was removed from the analysis due to high variance and low coverage. As a result, five sections of sets of induced genes were obtained (Fig. 1a, lower panel).

We combined biological explanations with members of certain Venn diagram cluster and intersections (Fig. 1a, red rectangles). Genes induced (Mfuzz $C>0$ ) during fermentation on 'Spruce + board Anaerobic' (1337 genes) combined with genes induced on 'Malt extract' (1420 genes) summed up to 2757 genes (Fig. 1a, lower panel). Together these sets of genes were described as Group 1 , of 'Anaerobically induced genes'. The second cluster of 194 genes included genes that were induced on all lignocellulose-containing substrates. Hence Group 2 was named 'Lignocellulose-induced genes under both atmospheres'. Group 3 includes the 1440 upregulated genes shared with cultivations 'Spruce+board Aerobic', 'Spruce 2 weeks' and 'Spruce 4 weeks'. This group was called 'Lignocellulose-induced genes under aerobic conditions.' Group 4 'Spruce wood substrate induced genes' includes 717 genes; and Group 5 'Spruce wood + core board substrate induced genes' includes 780 genes induced on the mixture of the lignocellulose waste substrates under aerobic and fermentative atmospheres.

Group 1 is the largest by number containing most of the induced genes among the core metabolism genes (Fig. 1c). Up to 93 of the 216 studied genes belong to Group 1 (anaerobically induced genes). This group, however, has little representation of CAZy genes, as only 15 out of the 113 CAZy genes clustered into Group 1 (Fig. 1b). The simultaneous presence of oxygen and lignocellulose is seemingly important for promoting expression of both CAZy encoding genes as well as genes involved in and core metabolism, since Group 3 was well represented in both cases (38 and 24 induced genes, respectively). Group 2 had 16 induced CAZy genes together with three induced genes involved in core metabolism. These three genes (plus.g1220, minus. 
g2306 and plus.g1349) appear to encode non-secreted, intracellular $\beta$-glucosidases (Additional file 1: Table S4). In brief, these findings imply that atmospheric changes have a major impact on expression of fungal CAZy genes.

\section{Expression of CAZy genes under different atmospheric conditions}

We analyzed the functional distribution of CAZy genes in each gene expression group. Surprisingly, of the 15 CAZy genes in Group 1, 12 genes were induced under the fermentative conditions on lignocellulose substrate, whereas malt extract medium induced expression of three genes. The 15 CAZy genes induced in Group 1 include 10 genes encoding cellulose-active enzymes (Table 1). Interestingly, three of these genes encode AA9 lytic polysaccharide monooxygenases (LPMOs), which are considered to require oxygen or hydrogen peroxide for catalytic activation [22]. Group 3 (lignocellulose-induced under aerobic conditions) included most of the expressed CAZy genes, comprising five AA9 LPMOs and many genes for activities against cellulose and hemicelluloses.

The majority of the pectin-active enzyme-encoding genes were included in Group 3 (Table 1). As expected, aerobic conditions induced the expression of ligninactive AA2 peroxidases (two genes for long-manganese peroxidases). Notably the AA2 peroxidases were absent from Group 2 (lignocellulose-induced genes under both atmospheres), which in contrast contains several genes encoding cellulose-active enzymes.

Lignocellulose substrates induced the expression of CAZy genes; two minor clusters of gene expression (Groups 4 and 5) were obtained from spruce wood (Group 4, on cultivation weeks 2 and 4) and the mixture of spruce wood sawdust and core board (Group 5). Group 4 contains five of the $P$. radiata AA2 lignin-active enzyme genes including lignin and manganese peroxidases (LiPs, $\mathrm{MnPs}$ ), together with three genes for hemicellulose activity and one GH7 cellobiohydrolase encoding gene (Table 1). In contrast, the lignocellulose mixture (spruce sawdust + core board) induced expression of six genes for pectin, six genes for hemicellulose degradative activity, but only one gene for cellulose degradative activity. Groups 1, 2 and 3 hold all of the endoglucanase-encoding CAZy GH5 genes (Table 1). The only laccase gene that has been detected also from proteome (plus.g7011) [4] was found to be repressed in fermentative conditions (Additional file 1: Table S4). In total, the five distinct gene expression groups explained expression of $81 \%$ (91 genes) of the 113 previously identified and functionally annotated $P$. radiata CAZy genes [19].

\section{Enzyme activity measurements}

Activities of extracellular $\beta$-glucosidase, endoglucanase, xylanase, pectinase (polygalacturonic acid depolymerization assay), manganese peroxidase and laccase enzymes were measured from the fungal cultures on spruce + core board substrate to confirm the findings of gene expression. Activities of cellulose-active enzymes (endoglucanase, $\beta$-glucosidase and cellobiohydrolase $\mathrm{CBH}$ ) were higher under fermentative conditions (spruce+board anaerobic) while the activities of xylanase and ligninmodifying enzymes were the opposite (Fig. 2). Depolymerization activity of polygalacturonic acid showed no difference between the cultivations. Enzyme activities normalized with total RNA showed that all other activities were significantly higher at fermentative conditions except laccase and $\mathrm{MnP}$ activities that were significantly higher in aerobic conditions (for total RNA-quantities, see "Materials and methods" RNA-Seq and transcriptome assembling). Surprisingly, $\beta$-glucosidase enzyme activity increased under fermentative conditions, although there was only one upregulated $\beta$-glucosidase encoding gene (minus.g7505) upon fermentative cultivation conditions (Additional file 1: Table S3). The enzyme encoded by this gene is also the only $\beta$-glucosidase that contains a CBM module.

\section{Promoter region analysis of the CAZy genes}

To find explanations for the expression patterns of the multiple and functionally divergent lignocellulosedecomposing CAZy encoding genes, we examined expression of known fungal DNA binding transcription factors such as ACE1-3, McmA, GaaR, XlnR, and Sxlr, which are regulators for genes coding for cellulose, hemicellulose and pectin degradative enzymes [23-26]. We looked for similar expression of the transcription factor-encoding genes and those CAZy genes predicted to possess the specific regulator binding sequence motifs on their promoter regions. This approach aimed to anticipate regulative factors that are effective for fungal extracellular and intracellular metabolism upon decomposition of lignocellulose.

In brief, we found no protein homologs of $P$. radiata for the ACE1-3, XlnR or Sxlr transcription factors described in plant biomass decomposing Ascomycota. Only a homolog for McmA activator was identified (P. radiata gene plus.g9031), which was noted to be induced during fermentation on the waste lignocellulose mixture but also on spruce wood after 2 and 4 weeks of cultivation. Although we found no homologs for ACE1-3, the binding motif $5^{\prime}$-GGCTAATAA-3' for ACE2 [27] was present $655-647 \mathrm{bp}$ and $651-643 \mathrm{bp}$ upstream of the promoter regions of two oxygen-depletion-induced GH7 
Table 1 Expression patterns of carbohydrate-active enzyme encoding genes of $P$. radiata

\begin{tabular}{|c|c|c|c|c|c|c|c|}
\hline Cellulose active & CAZy & Hemicellulose active & CAZy & Pectin active & CAZy & Lignin active & CAZy \\
\hline \multicolumn{8}{|c|}{ Group 1: anaerobically induced genes } \\
\hline plus.g8293 & AA9 & plus.g13357 & $\mathrm{GH} 10$ & plus.g1493 & $\mathrm{GH} 28$ & & \\
\hline plus.g10695 & AA9 & minus.g4431 & $\mathrm{GH} 31$ & plus.g10556 & GH105 & & \\
\hline minus.g531 & AA9 & plus.g1199 & $\mathrm{GH} 31$ & & & & \\
\hline minus.g2565 & GH5_5 & & & & & & \\
\hline minus.g2003 & $\mathrm{GH7}$ & & & & & & \\
\hline plus.g2026 & $\mathrm{GH7}$ & & & & & & \\
\hline minus.g8589 & $\mathrm{GH7}$ & & & & & & \\
\hline plus.g13166 & GH9 & & & & & & \\
\hline minus.g170 & $\mathrm{GH} 45$ & & & & & & \\
\hline plus.g7035 & $\mathrm{GH} 45$ & & & & & & \\
\hline \multicolumn{8}{|c|}{ Group 2: lignocellulose-induced genes under both atmospheres } \\
\hline minus.g10273 & AA9 & plus.g12321 & CE1 & minus.g3209 & $\mathrm{GH} 28$ & & \\
\hline plus.g9320 & AA9 & minus.g10669 & CE15 & & & & \\
\hline minus.g8537 & GH5_5 & minus.g10025 & CE16 & & & & \\
\hline minus.g2832 & GH5_22 & minus.g319 & GH5_7 & & & & \\
\hline plus.g2874 & GH5_22 & plus.g3697 & $\mathrm{GH} 11$ & & & & \\
\hline plus.g4342 & $\mathrm{GH6}$ & minus.g5676 & GH35 & & & & \\
\hline minus.g169 & $\mathrm{GH} 45$ & minus.g7290 & $\mathrm{GH} 74$ & & & & \\
\hline plus.g5796 & $\mathrm{GH} 131$ & & & & & & \\
\hline \multicolumn{8}{|c|}{ Group 3: lignocellulose-induced genes under aerobic conditions } \\
\hline plus.g9628 & AA3_1 & minus.g2146 & AA5 & plus.g11923 & CE8 & plus.g1419 & MnP1-long \\
\hline minus.g10274 & AA9 & minus.g1785 & CE15 & plus.g5896 & CE8 & plus.g10562 & MnP2-long \\
\hline minus.g3552 & AA9 & minus.g3957 & CE16 & plus.g6259 & $\mathrm{GH} 28$ & & \\
\hline plus.g11539 & AA9 & plus.g637 & CE16 & minus.g11678 & $\mathrm{GH} 28$ & & \\
\hline plus.g11538 & AA9 & minus.g9090 & CE16 & minus.g10006 & $\mathrm{GH} 28$ & & \\
\hline plus.g13374 & AA9 & plus.g9565 & $\mathrm{GH} 2$ & minus.g4364 & GH53 & & \\
\hline minus.g2505 & $\mathrm{GH} 3$ & plus.g7205 & GH5_7 & minus.g8873 & PL4 & & \\
\hline plus.g7451 & GH5_5 & minus.g11036 & $\mathrm{GH} 10$ & & & & \\
\hline minus.g2568 & GH5_5 & minus.g12190 & $\mathrm{GH} 10$ & & & & \\
\hline plus.g8163 & $\mathrm{GH} 7$ & minus.g11656 & $\mathrm{GH} 10$ & & & & \\
\hline minus.g5721 & $\mathrm{GH} 12$ & minus.g11034 & $\mathrm{GH} 10$ & & & & \\
\hline plus.g1671 & GH44 & minus.g5675 & GH35 & & & & \\
\hline \multirow[t]{4}{*}{ minus.g9081 } & GH131 & minus.g4481 & $\mathrm{GH} 43$ & & & & \\
\hline & & plus.g1633 & GH51 & & & & \\
\hline & & minus.g9719 & GH95 & & & & \\
\hline & & minus.g5364 & GH115 & & & & \\
\hline \multicolumn{8}{|c|}{ Group 4: spruce wood substrate induced genes } \\
\hline \multirow[t]{5}{*}{ minus.g5595 } & $\mathrm{GH} 7$ & minus.g7380 & CE1 & & & minus.g3073 & LiP1 \\
\hline & & plus.g12991 & $\mathrm{GH} 2$ & & & minus.g6827 & LiP2 \\
\hline & & minus.g11037 & $\mathrm{GH} 10$ & & & plus.g11059 & LiP3 \\
\hline & & & & & & plus.g453 & MnP3-short \\
\hline & & & & & & minus.g3827 & MnP6-long \\
\hline \multicolumn{8}{|c|}{ Group 5: spruce wood + core board mixture substrate induced genes } \\
\hline \multirow[t]{6}{*}{ plus.g9738 } & $\mathrm{GH} 12$ & minus.g3390 & GH5_7 & plus.g1505 & $\mathrm{GH} 28$ & & \\
\hline & & plus.g8530 & $\mathrm{GH} 27$ & minus.g11677 & $\mathrm{GH} 28$ & & \\
\hline & & minus.g9779 & $\mathrm{GH} 29$ & plus.g9417 & GH78 & & \\
\hline & & plus.g11941 & GH35 & minus.g2361 & GH78 & & \\
\hline & & minus.g11462 & $\mathrm{GH} 43$ & plus.g9742 & GH105 & & \\
\hline & & minus.g10886 & GH74 & minus.g12950 & GH105 & & \\
\hline
\end{tabular}

Division of CAZy genes into five groups of differentially expressed genes is presented in Fig. 1. Genes are listed according to enzyme function and substrate specificity. CAZy genes were annotated previously $[4,19]$ 


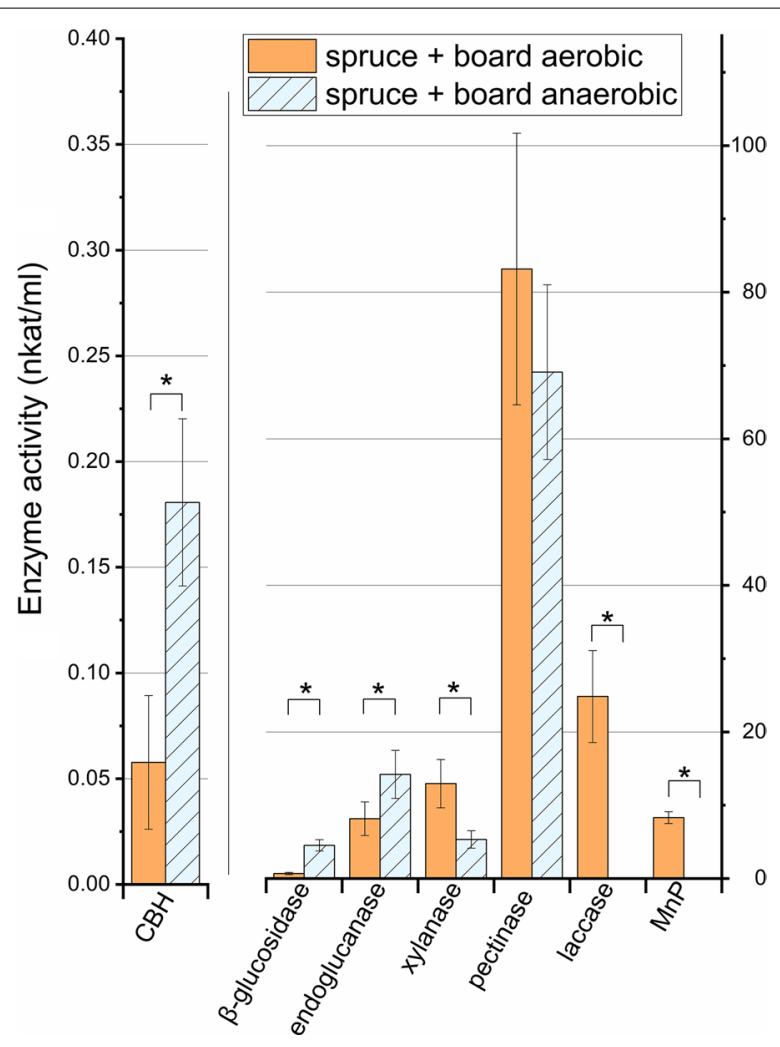

Fig. 2 Enzyme activities of P. radiata. Comparison of cellulose, hemicellulose, pectin and lignin-active extracellular enzyme activities measured from cultivation day 14 on spruce + board aerobic and anaerobic. Notice the different $y$-axis for $\mathrm{CBH}$ at the left. Brackets with asterisk define statistical differences between culture atmospheres $(p<0.01)$. CBH, cellobiohydrolase; MnP, manganese peroxidase. Bars represent the mean value of three parallel culture flasks while error bars represent standard deviation

cellobiohydrolase encoding genes (minus.g2003 and plus. g2026, respectively) (Table 1). Interestingly, this specific motif was not detected on the promoter regions of any other P. radiata CAZy genes. Search for the Aspergillus niger pectin usage transcription factor GaaR [28] gave only two distant hits (genes minus.g11147 and minus.g9788). However, we found no GaaR binding motif on the promoters of $P$. radiata genes encoding pectin-active enzymes or genes involved in metabolism of galacturonic acid.

MEME search discovered an enriched motif $5^{\prime}$-SGTA TAAA-3' of unknown function from promoter regions of $P$. radiata genes. This motif was recognized on the promoter regions of four CAZy pectin degradation-encoding genes as well as three genes encoding specific intracellular NADPH-dependent reductases (enzyme functions [EC 1.1.1.372], [EC 1.1.1.365] and [EC 1.1.1.21]), most likely involved in the catabolism of carbohydrates released from pectin and hemicelluloses. In addition, promoter regions of all lignin-modifying AA1 and AA2
CAZy class genes possessed the motif 5'-SGTATAAA-3'. This motif located once 74-117 nucleotides upstream from the translational coding sequence start codon. A similar motif has been reported to be present on the promoters of lignin-active AA2 CAZy genes in white rot fungi [29].

\section{Carbohydrate consumption of $P$. radiata under varying atmospheres}

To reveal how the intracellular carbohydrate-utilizing metabolism responded to the changes in culture atmosphere, we cultivated $P$. radiata on various monosaccharides (glucose, galactose, mannose, and xylose), and polysaccharides (polygalacturonic acid and pectin) as the sole carbon sources. Fungal mycelium used all studied monosaccharides as well as pectin and polygalacturonic acid as substrates under both cultivation atmospheres (Fig. 3a, c). Galactose was consumed fastest of the monosaccharides followed by mannose, glucose and xylose. From pectin, accumulation of galacturonic acid as degradation product was increased under fermentative conditions (Fig. 3c). Surprisingly, ethanol was also detected under aerobic conditions in cultivations on almost all of the studied carbohydrate substrates as well as from aerobic cultures on the solid lignocellulose "spruce + board aerobic" (Fig. 3a, b).

The intake and conversion of glucose and mannose was faster under fermentative atmosphere than under aerobic conditions (Fig. 3a, c). Galactose or xylose uptake showed no difference within 15 days between atmospheres. P. radiata converted the waste lignocellulose mixture (spruce wood sawdust + core board), leading to an accumulation of ethanol, up to $10 \mathrm{~g} / \mathrm{L}$ in 49 days under fermentative conditions (Fig. 3d). In addition, we detected production of extracellular glycerol $(0.14-0.27 \mathrm{~g} / \mathrm{L})$ and a moderate amount of acetate $(0.6-1.5 \mathrm{~g} / \mathrm{L})$ from the lignocellulose substrate under fermentative conditions. We calculated the carbohydrate content of the substrate (1 $\mathrm{g}$ of core board [30] and $4 \mathrm{~g}$ of spruce wood sawdust [31] to estimate the quantity of utilizable hexose sugars in the substrates. Based on stoichiometry, we calculated the quantity of hexose sugars required to produce the detected quantities of ethanol glycerol and acetate. After 14 days of cultivating $P$. radiata under fermentative conditions on the lignocellulose substrate, $8.7 \%$ of its total hexose sugars was required to produce $4.8 \mathrm{~g} / \mathrm{L}$ of ethanol, $1.13 \mathrm{~g} / \mathrm{L}$ of acetate and $0.17 \mathrm{~g} / \mathrm{L}$ of glycerol. Prolonging the cultivation up to 49 days resulted in $16.3 \%$ of hexose sugars to be converted into end products. Cultivation on natural-type pectin substrate under both aerobic and fermentative conditions led into slight accumulation of methanol (Fig. 3a, c). 


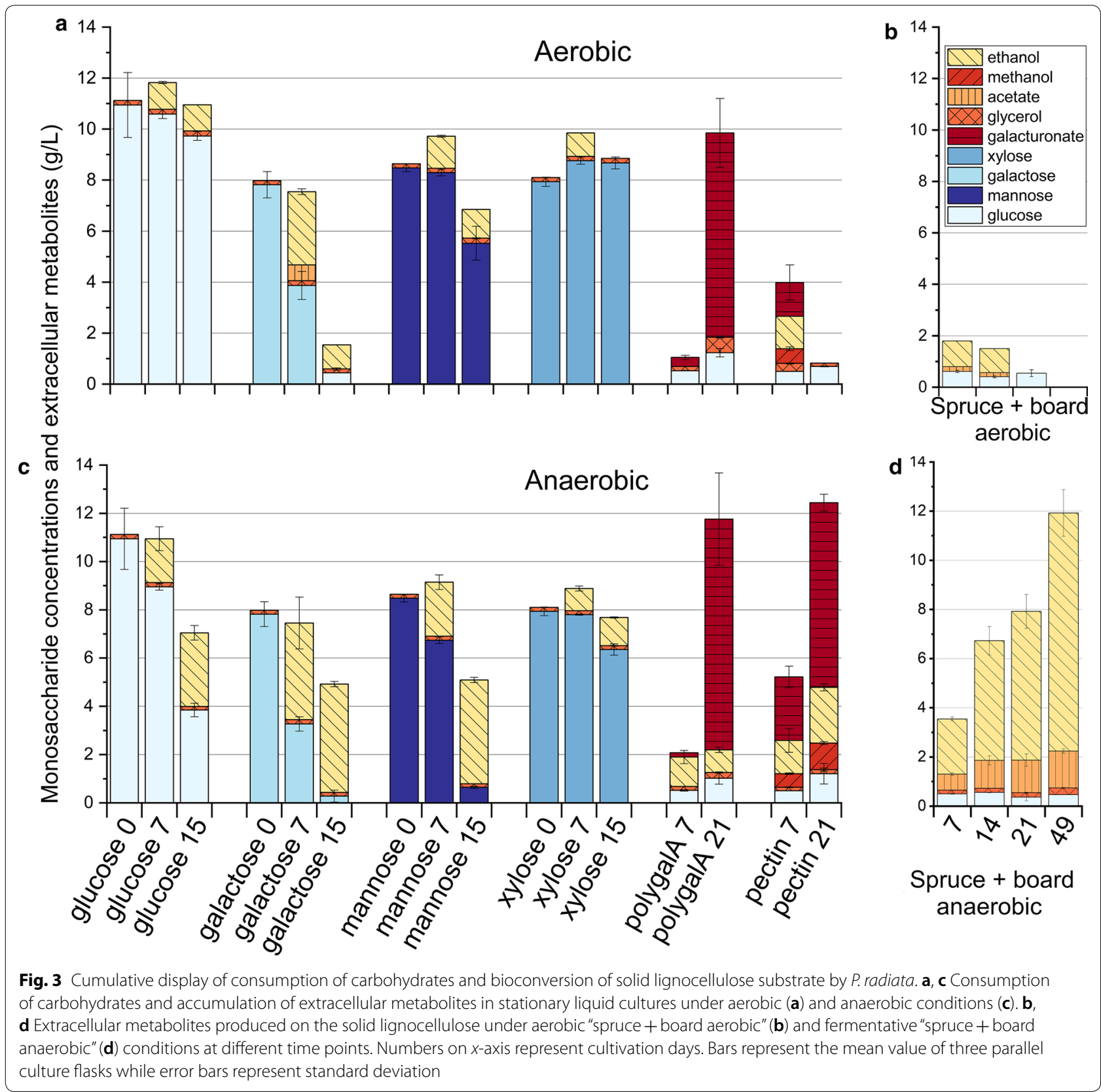

\section{Intracellular metabolism under hypoxia}

Oxygen depletion while growing on lignocellulose substrates affected the intracellular metabolism of $P$. radiata by inducing expression of 93 core metabolic genes (Fig. 1c). Thus, we studied the impact of oxygen depletion leading to hypoxia on expression of genes of intracellular metabolism by calculating the transcriptome fold changes between conditions of 'Spruce + board Anaerobic' and 'Spruce + board aerobic. Genes encoding proteins involved in the intracellular primary metabolism of glycolysis and Leloir pathways as well as glycerol metabolism and triglyceride degradation and biosynthesis and phosphoketolase pathway, were upregulated under hypoxia (Fig. 4) (Additional file 1: Table S4). Phosphoketolase pathway produces acetate/secreted acetic acid through acetyl phosphate (Fig. 4). In addition, genes involved in oxidative phosphorylation and especially those encoding mitochondrial complexes III, IV and ATP synthase were upregulated (Additional file 1: Table S4). In contrast, fatty acid $\beta$-oxidation, pectin degradation catabolism, and parts of ergosterol biosynthesis pathways 
were either constant in expression or repressed under hypoxia. Based on expression patterns of genes coding for ethanol dehydrogenases [EC 1.1.1.1] and aldehyde dehydrogenases [EC 1.2.1.4], pyruvate was most likely converted into ethanol instead of acetate (Fig. 4).

\section{P. radiata phosphoketolase pathway and acetyl kinase enzymes}

We investigated more closely the phosphoketolase [EC 4.1.2.9] candidate protein encoded by the homologous $P$. radiata gene plus.g11264, which has been detected

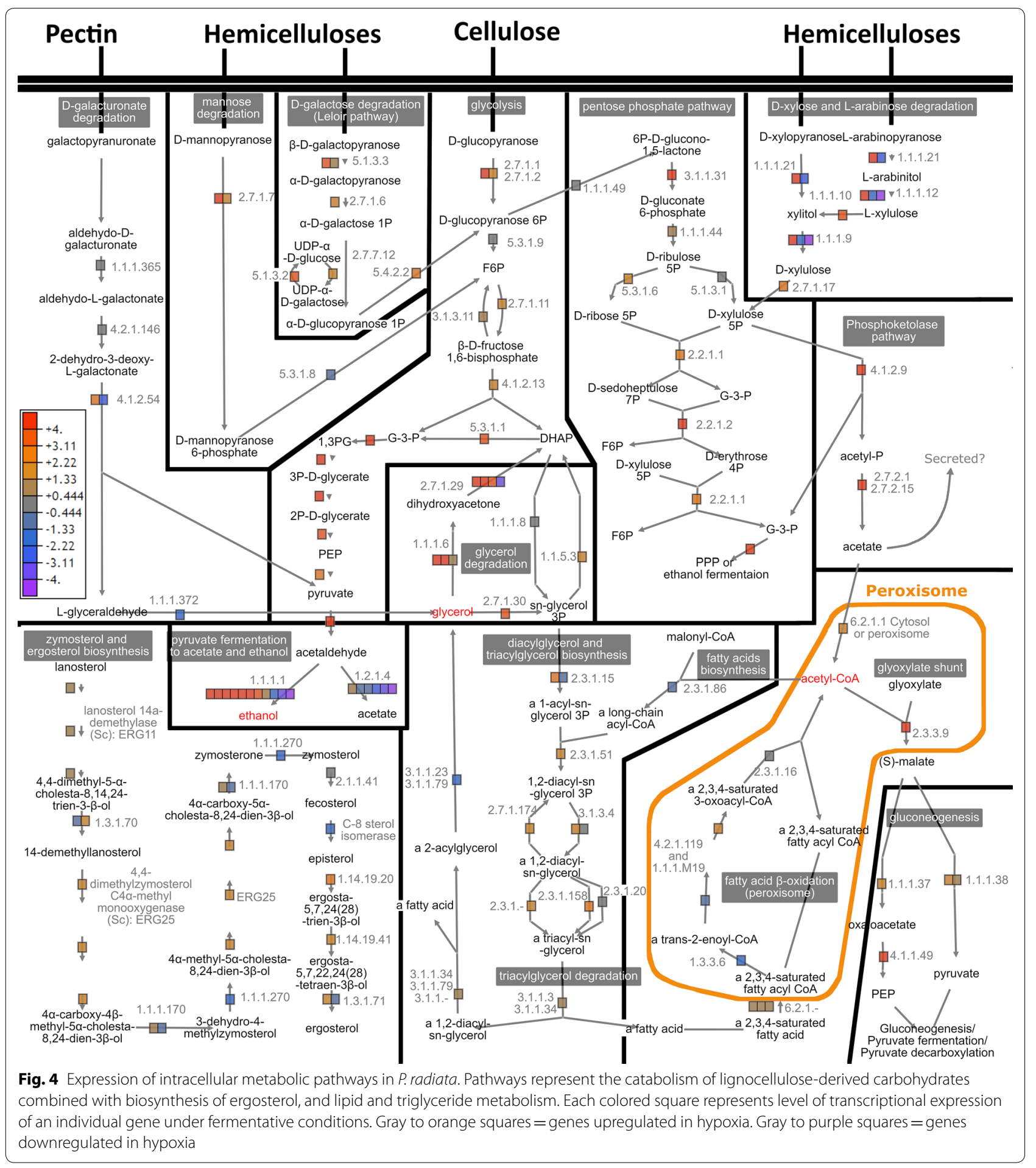


also as a peptide in a previous proteome study [4]. The translated protein candidate showed $36 \%$ amino acid sequence identity with the phosphoketolase of Bifidobacterium breve (D6PAH1, Uniprot accession) and 43\% identity with Cryptococcus neoformans predicted protein (J9VR37, Uniprot) [32], respectively (Additional file 2). Protein folding structural similarity between $P$. radiata and C. neoformans models was $37 \%$. Analysis of the translated $P$. radiata protein model plus.g11264 and J9VR37 adopting PHYRE2 Protein fold recognition server (http:// www.sbg.bio.ic.ac.uk/ phyre2) revealed that the conserved binding sites for coordinated Ca-ion and the thiamine pyrophosphate (TPP) ligands were found in both $P$. radiata and C. neoformans enzyme models. Superposition of the 3D protein models turned out to be identical with the $B$. breve phosphoketolase crystal structure model 3AHC (RCSB protein database) (Additional files 3 and 4).

The second enzyme of phosphoketolase pathway, acetate kinase [EC 2.7.2.1] is responsible for the conversion of acetyl phosphate (product of phosphoketolase activity) to acetate. The translated predicted protein for acetate kinase gene (plus.g11263) demonstrated amino acid sequence identity of $37 \%$ with C. neoformans acetate kinase model (J9W3A6, Uniprot) that has been structurally characterized (crystal structure 4HOP, RCSB PDB database) [33]. Both the $P$. radiata protein model and $C$. neoformans acetate kinase enzymes possess the conserved ligand binding sites for ATP. Similar to phosphoketolase, these two proteins share an identical 3D structure based on homology modeling and superposition analysis.

\section{Transcription factors and regulation of primary metabolism under hypoxia}

In order to understand the regulation behind carbohydrate metabolism, we focused on transcription factors involved in fungal metabolic pathways of carbon usage (Table 2) and ergosterol biosynthesis. We searched potential candidates for known transcription factors in $P$. radiata based on protein homology. We analyzed expression of transcription factor genes candidates by comparing their expression fold changes between aerobic and fermentative conditions, similarly as described above.

The fungal transcription factor-encoding genes associated with non-fermentative carbon utilization were constitutively expressed between aerobic and fermentative conditions (fold change $\leq 1$ and $\geq-1$ ) or downregulated during fermentation (fold change $\leq-1$ ). As exceptions, the orthologous genes encoding transcription factor ERT1-like homolog of C. neoformans and Adr1-like homolog, both genes were upregulated under fermentative conditions. The predicted $P$. radiata gene for Adr1 shows remarkable induction under hypoxia (Table 2).

Ergosterol synthesis is crucial for sensing hypoxia in fungi, and has been reported to respond to low oxygen tension and other stress factors in the Ascomycota fission yeast Schizosaccharomyces pombe [39]. The closest ortholog of the fungal ergosterol biosynthesis regulatorelement binding protein (SREBP) encoding gene in $P$. radiata (gene minus.g3490) was constitutive in expression under fermentative conditions. However, the identity of translated amino acid sequences is only $16 \%$ between $P$. radiata and the other Basidiomycota species C. neoformans Sre candidates.

Next, we analyzed the presence of the Adr1 transcription factor DNA binding motif $5^{\prime}$-TGCGGGGA-3' [32] in promoter regions of $P$. radiata core metabolism and CAZy (Additional file 1: Table S4). Of the 33 genes involved in intracellular metabolism of $P$. radiata that demonstrated to possess the Adr1 transcription factor binding motif in $5^{\prime} \rightarrow 3^{\prime}$ direction, up to 25 were induced during fermentation on the mixed lignocellulose substrate ('Spruce + core board Anaerobic') (Fig. 5).

Table 2 Transcription factors of fungi involved in carbon metabolism

\begin{tabular}{|c|c|c|c|c|c|}
\hline Function & Uniprot entry & $\begin{array}{l}\text { Reference organism } \\
\text { for protein homolog }\end{array}$ & Protein name & P. radiata ortholog & $\begin{array}{l}\text { Effect } \\
\text { of oxygen } \\
\text { depletion }\end{array}$ \\
\hline Ethanol regulated TF. activates PEP synthesis [34] & CNAG_04588 & C. neoformans & ERT1 & plus.g634 & 1.01 \\
\hline Non-fermentable carbon usage [35] & CNAG_02215 & C. neoformans & Нар3 & minus.g3547 & -1.54 \\
\hline Non-fermentable carbon usage [35] & CNAG_07680 & C. neoformans & Hap5 & minus.g13227 & -0.97 \\
\hline Carbon catabolite repression regulator [36] & $\begin{array}{l}J 9 W 323 \\
\text { P27705 }\end{array}$ & $\begin{array}{l}\text { C. neoformans } \\
\text { S. cerevisiae }\end{array}$ & $\begin{array}{l}\text { CreA } \\
\text { Mig1 }\end{array}$ & plus.g8859 & -0.01 \\
\hline Gluconeogenesis activator [37] & P39113 & S. cerevisiae & Cat8 & plus.g8696 & -0.84 \\
\hline Alternative carbon usage [38] & P07248 & S. cerevisiae & Adr1 & minus.g541 & 3.2 \\
\hline
\end{tabular}

Gene expressional change in hypoxia, fold change $\geq 1$ upregulated under hypoxia

PEP, phosphoenolpyruvate; TF, transcription factor 
In addition, three of the CAZy GH7 genes contained the Adr1 binding motif on their promoter regions (Additional file 1: Table S4). Interestingly, promoters for genes active in xylose reductive pathway, pentose phosphate pathway (PPP), and phosphoketolase pathway, glyoxylate shunt and glycerol metabolism possessed this binding motif (Fig. 5).

\section{Discussion}

Decomposition of wood and plant biomass lignocelluloses by Basidiomycota wood-decaying fungi is an extracellular process, requiring secreted hydrolytic and oxidoreductase enzymes (CAZymes and auxiliary enzymes) $[2,4,6,7,40]$. Therefore, these biological systems have been studied under aerobic experimental conditions. However, the ability to ferment carbohydrates and lignocelluloses into ethanol, particularly by the species of the genus Phlebia (order Polyporales) [15, 41] has pinpointed the need to explore the fungal metabolic pathways and their regulation under oxygen-depleted conditions. Our study is the first complete transcriptomic investigation that compares fermentative and aerobic cultivation conditions, in order to explain the cellular events of fungal decay of wood and lignocellulose concomitant with ethanol fermentation under hypoxia. P. radiata possess a wide array of secreted lignocellulose-decomposing enzymes $[4,18,19]$, but in addition, it possesses the pathways required for the catabolism of the released galacturonic acid, pentose and hexose sugars (Fig. 4).

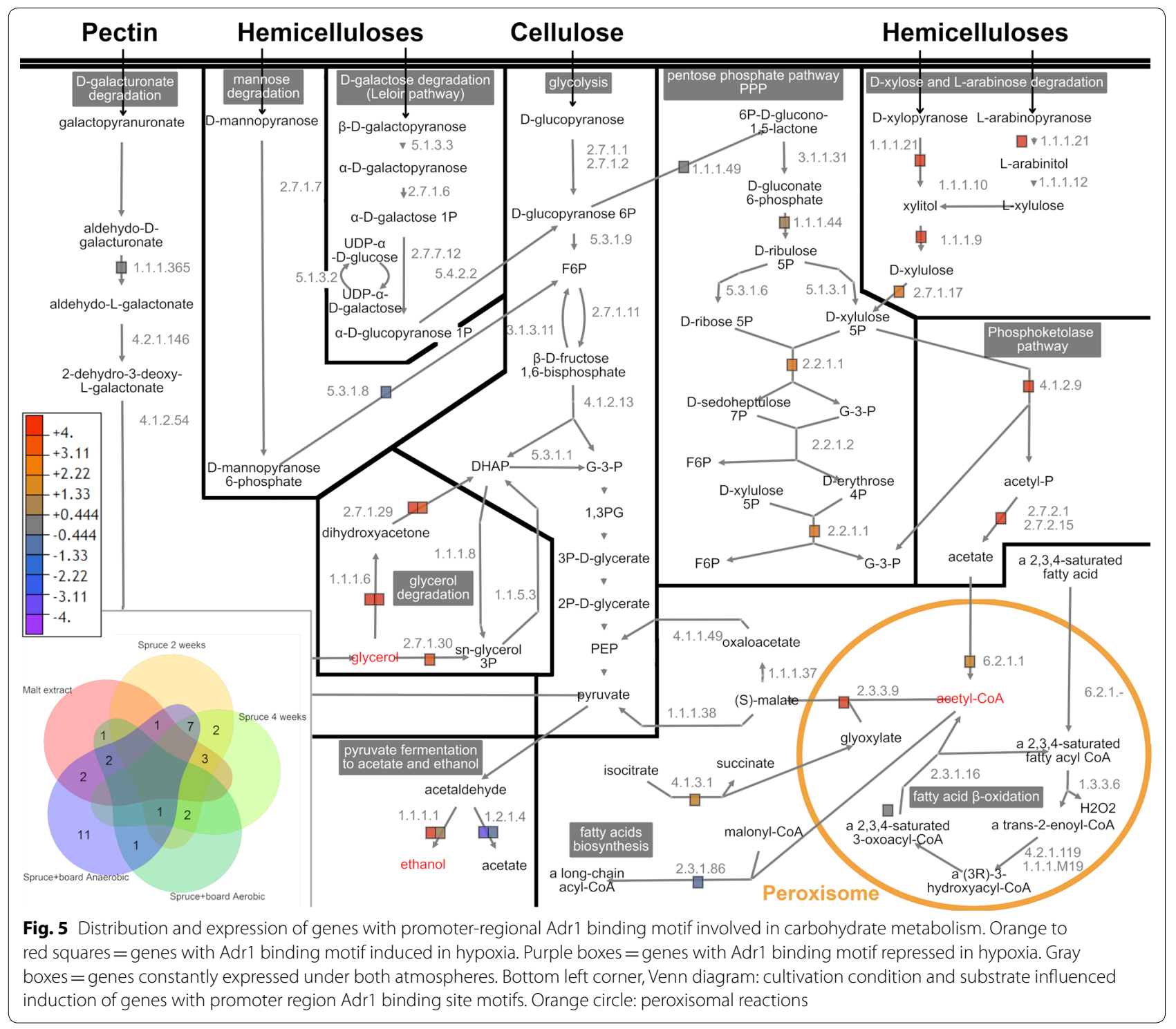


In other species of Polyporales white rot fungi such as Phanerochaete chrysosporium, Phanerochaete carnosa, Cerrena unicolor, and Pycnoporus cinnabarinus, the type of wood and lignocellulose substrate directs the transcriptional expression of CAZy genes [42-45]. In our study on $P$. radiata, we found that atmospheric transition is the key regulator of CAZy genes encoding celluloseactive enzymes. The composition of the carbon source or substrate regulated only two cellulose-active CAZy genes (Groups 4 and 5). In contrast, expression of up to $23 P$. radiata CAZy genes encoding cellulose-active enzymes was regulated by transition of the culture atmosphere from aerobic to oxygen-depleted fermentative state (Groups 1 and 3).

Remarkably, hypoxic conditions induced the expression of up to 10 genes for cellulose-degradative CAZymes in $P$. radiata, which was also detected in enzyme activity measurements. It remains undefined whether LPMO activity affected the activity results as the enzyme activity measurement was conducted in aerobic conditions. Regarding decomposition of plant cell wall lignocelluloses, CAZy enzyme families GH6 and GH7 of cellobiohydrolases are important for cleaving crystalline regions of cellulose chains [2, 7]. Of the six GH7 genes of $P$. radiata $[4,19]$, hypoxia induced expression of three genes (in Group 1). The other GH7 genes and the single GH6 gene clustered to the other gene expression groups. Since CBH enzyme activity was detected under both atmospheric conditions, therefore it is thereby plausible that all six predicted GH7 enzymes of $P$. radiata have an important role in lignocellulose degradation.

Regarding lytic polysaccharide mono-oxygenases, out of the 12 genes encoding $P$. radiata AA9 LPMOs [19], seven genes were induced by lignocellulose (five in Group 3, and two in Group 2). To our surprise, fermentative conditions specifically induced three AA9 genes clustered to Group 1. Concerning the regulation of cellulose actin enzymes encoding genes, a homolog for McmA previously described in filamentous fungi [46] was the only candidate found in the $P$. radiata genome. Therefore, it is likely that regulation of the cellulose-active genes in this fungus is very different from the mechanisms reported for Ascomycota species, and requires further investigation.

Oxygen depletion repressed the expression of a number of hemicellulose-active CAZymes in $P$. radiata, which was consistent with detected extracellular xylanase enzyme activity. On the contrary, the growth substrate apparently regulated the expression of pectin-degradation active CAZy genes. The mixture of spruce wood sawdust and core board induced the expression of genes encoding enzymes for rhamnose degradation. One of the GH28 enzyme-encoding genes (plus.g1493) was among the highest upregulated genes on comparing anaerobic to aerobic culture conditions (Spruce + board anaerobic and Spruce + board anaerobic), indicating an important role in pectin utilization by the fungus under fermentative conditions. This is concurrent with the finding that the fungus demonstrated polygalacturonic acid depolymerizing activity and consumption under both atmospheric conditions, and was able to utilize this carbohydrate polymer as a carbon source under fermentative conditions. Galacturonic acid seemed to accumulate into the cultivation liquid as degradation product from pectin and polygalacturonic acid. Lack of detection of the product from pectin under aerobic atmosphere may be due to inefficient degradation of pectin or efficient intake and consumption of galacturonic acid. P. radiata is a wooddecomposing white rot fungus [4] that encounters pectin polysaccharides in its natural substrate (dead wood), mainly in the middle lamellae of xylem wood cells. Noticeably, various GH28 pectin-active CAZymes have been detected in the proteome of the fungus expressed on spruce wood [4]. Culture liquids under fermentative conditions possessed no laccase or MnP activity, which was consistent with the transcriptome analyses demonstrating the lack of stimulation for expression.

Our results point towards co-regulation of the fungal intracellular primary metabolism and lignocellulosedecomposing, secreted CAZymes. Extracellular pectin-degradation active genes and genes responsible for intracellular catabolism of galacturonic acid were both assigned to Group 3. This indicates that the extracellular and intracellular metabolic reactions and pathways for pectin degradation may operate under shared regulation as is reported for species of Aspergillus [47]. However, despite the noticed co-expression of enzyme-encoding genes involved in pectin decomposition and conversion of galacturonic acid, we could not detect Aspergillus GaaR transcription factor binding site [47] within $P$. radiata promoter regions. In fact, we found no such enriched motifs on the promoters of pectin metabolic genes, which could have explained this co-expression. Understanding the shared regulation between lignocellulose-degradative CAZyme encoding genes and intracellular metabolic pathways is necessary for microbial biotechnology approaches aiming at fungal applications. Efficient bioconversion of the secondary carbohydrate polysaccharides of lignocellulose, that is hemicelluloses and pectins, is mandatory for establishing sustainable second-generation production of bioethanol.

\section{Adaptation to hypoxia by regulation of intracellular metabolism}

Based on the large number of upregulated genes shared between "Spruce + board anaerobic" and "Malt extract" 
cultivations, we concluded that the submerged mycelium might encounter hypoxia under non-agitated conditions. Similar outcome was recently reported for the Ascomycota species Cordyceps militaris [48]. This is consistent with minor ethanol accumulation detected from liquid media under aerobic cultivations. Although, ethanol was also detected under aerobic cultivations we determined that $P$. radiata is a "Crabtree-negative" organism based on the induction of glycolysis under hypoxia or alternatively, repression of metabolic genes functional in glycolysis and fermentation under aerobic conditions. In the budding yeast $S$. cerevisiae, a "Crabtree-positive" effect refers to the ability to produce ethanol under aerobic conditions and high glucose concentrations which is seen also in gene expression $[49,50]$. These results reinforce the primary interpretation of our results that upon wood decomposition, wood-decaying fungi encounter partial hypoxia, leading to fermentation and ethanol production.

Hypoxia does not repress the catabolism of carbohydrates in $P$. radiata. Transcription factor CreA and catabolic pathways involved in less favorable carbon sources of $P$. radiata were not induced under hypoxia. Therefore, we concluded that concentration of glucose or other carbohydrates was not high enough to induce carbon catabolite repression [51] under hypoxia. Expression of the diauxic shift-associated transcription factor Cat8 candidate in $P$. radiata [37] followed a similar pattern to CreA. In S. cerevisiae, Cat8p targets a gluconeogenesis-related fructose-bisphosphatase [EC 3.1.3.11], which was constitutively expressed in $P$. radiata. In contrast to CreA and Cat8 homologs, the expression of transcription factor ERT1 and its target gene phosphoenolpyruvate carboxykinase [EC 4.1.1.49], were induced in $P$. radiata under fermentative conditions. In conclusion, we suggest that $P$. radiata is enforcing catabolism of hexose and pentose sugars in hypoxia state. Based on differential gene expression, less favorable carbon sources such as glycerol, TCA-derived organic acids, and acetate are simultaneously transformed into PEP and pyruvate that are likely routed to ethanol fermentation instead of gluconeogenesis (Fig. 4).

Stimulation of ergosterol synthesis is a known adaptation to hypoxia in fungi such as the Ascomycota fission yeast S. pombe, and Basidiomycota human-opportunistic pathogen C. neoformans $[39,52]$. As our data show, expression of ergosterol biosynthetic pathway genes was, partially induced in P. radiata. Interestingly all enzymes in this pathway that require molecular oxygen as cofactor are slightly upregulated fold change $>1$. Several Basidiomycota species do not have Sre homolog [53]. Due to low homology between Sre candidates, it remains possible that $P$. radiata belongs to this group of fungi with different type of ergosterol regulation.
Glycerol metabolism of $P$. radiata was highly upregulated under hypoxia. This is noteworthy because, the culture media were not supplemented with glycerol, and extracellular glycerol production levels remained low throughout the experiments. Glycerol formation acts also as a parallel pathway to ethanol fermentation ensuring an adequate concentration of cytosolic NAD+, which ensures the functionality of glycolysis during hypoxia. Based on the expression data, glycerol was further utilized in triglyceride synthesis or mitochondrial glycerol phosphate shuttle [54]. We noticed that in addition to the activity of flavoprotein dehydrogenase [EC 1.1.5.3], which is required for the electron shuttle, oxidative phosphorylation complexes III, IV and V (ATP synthase) are induced under hypoxia. This shuttle transfers protons and electrons from DHAP into mitochondrial FAD thus regenerating even more NAD+ in cytosol. In conclusion, our findings concerning the expression of oxidative phosphorylation, glycerol, fatty acid and triglyceride metabolisms combined with ergosterol biosynthesis, which is not required for mitochondria biosynthesis [55], all point out that mitochondrial metabolism and biogenesis may have a central role under hypoxia.

\section{Phosphoketolase pathway and transcription factor Adr1 in $P$. radiata}

It has been proposed that Adr1 regulates the use of nonfermentable carbon sources in fungi, by inducing genes involved in conversion of ethanol into acetyl-CoA and incorporating glycerol into glycolysis or gluconeogenesis $[38,56]$. In addition, Adr1 has been associated with induction of aldehyde dehydrogenases, $\beta$-oxidation and induction of genes encoding catalases that play crucial roles for instance in $\beta$-oxidation by breaking down hydrogen peroxide [38, 56, 57]. Our results (Fig. 5) notably deviate from the previous studies on Ascomycota Adr1 using cultivation conditions of normal atmospheric oxygen levels, or on laboratory culture media containing for instance glycerol as carbon source.

Interestingly, we detected accumulation of secreted acetate in cultures on lignocellulose substrate under fermentative conditions where the NAD+/NADH ratio is usually low [58]. Since acetate production from ethanol or acetaldehyde via aldehyde dehydrogenase [EC 1.2.1.4] requires $\mathrm{NAD}+$ we concluded, there might be alternative acetate producing routes. Homologs for other acetate producing enzymes (succinyl-CoA: acetate CoAtransferase [EC 2.8.3.18] and acetyl-CoA hydrolase [EC 3.1.2.1]) were not found in $P$ radiata. Therefore, we suggest that phosphoketolase pathway is involved in the production of extracellular acetate as previously suggested in C. neoformans [32]. 
Promoters of $P$. radiata genes involved in the PPP and D-xylulose-5-phosphate phosphoketolase pathways carried the Adr1 binding motif. The motif is also present on promoters of genes involved in acetyl-CoA conversion leading to malate in the cytosol. Therefore, it remains unclear whether the activation of phosphoketolase pathway under hypoxia leads solely to production of acetate and ATP [32], or whether acetate and ATP are further transformed into acetyl-CoA [59]. In $P$. radiata, expression of mitochondrial acetyl-CoA synthetase [EC 6.2.1.1] encoding gene (minus.g1298) was constitutive while another gene (plus.g1345) encoding acetyl-CoA synthetase without any mitochondrial target peptide was upregulated. This indicates that during hypoxia $P$. radiata may convert part of the acetate into acetyl-CoA outside mitochondria, possibly in peroxisomes. Acetyl-CoA is required in peroxisomal glyoxylate shunt to generate malate, which can be transformed for instance to pyruvate. Based on differential gene expression in $P$. radiata, the source of peroxisomal acetyl-CoA is more likely the phosphoketolase pathway rather than $\beta$-oxidation. Therefore, we propose that phosphoketolase pathway may facilitate production of acetyl-CoA. Only few reports exist discussing the role of phosphoketolase pathway in eukaryotic organisms. However, hypoxiaassociated upregulation of phosphoketolase pathway encoding genes was observed in human pathogen C. neoformans [60], which is in accordance with our results on P. radiata.

Interestingly, extracellular acetic acid was detected only on the cultures "Spruce + board anaerobic", but not on liquid medium with monosaccharides as the sole carbon source. It has been suggested that production of acetate aids in decreasing extracellular $\mathrm{pH}$ in infections caused by Cryptococcus [32]. In the Polyporales wooddecaying fungi, increasing acidity is promoting lignocellulose degradation $[2,3,5]$. However, acidification of the environment is mainly due to production and secretion of oxalic acid $[15,61]$. Under hypoxia, $P$. radiata requires phosphoketolase pathway for the biosynthesis of both of these acids.

In addition, the phosphoketolase pathway provides an alternative for PPP. Although the ATP yield per glucose is lower in comparison to PPP, phosphoketolase pathway can replenish acetyl-CoA availability for fatty acid metabolism and synthesis of lipids and membranes, which are important adaptations under hypoxia [62]. Thus, the phosphoketolase route may serve as another adaptation providing metabolic flexibility for wood-decaying fungi under alternating atmospheric and environmental conditions. Describing the role and function of the phosphoketolase pathway in filamentous fungi requires further investigation.

\section{Conclusions}

Our results indicate that oxygen availability and substrate carbon source are both important regulators for expression of the secreted CAZy enzymes needed by wood-decaying fungi for degradation of lignocellulose and wood. Atmosphere appears to play a major role, especially in expression of cellulose-degrading CAZy genes, while the chemical composition of the lignocellulose substrate apparently influences expression of pectin-degrading CAZy genes. CAZy-regulating protein homologs differed between Ascomycota and P. radiata. This is not surprising, since the gene transcription factors in Ascomycota and Basidiomycota differ significantly [63] suggesting that the regulatory systems have evolved after these two fungal phyla diverged (about 570 million years ago) $[7,64]$. Further studies are required to reveal how the enzyme cocktail produced by $P$. radiata in anaerobic or fermentative conditions could be utilized in industrial processes. P. radiata can utilize and ferment various carbohydrates. In addition, phosphoketolase pathway was induced under hypoxia. The role of this pathway requires further investigations to fully understand its role in eukaryotic organisms.

\section{Materials and methods}

\section{Fungal isolate}

Phlebia radiata 79 (FBCC 0043) was adopted as the target organism due to (i) its previous success in ethanol production from various lignocelluloses $[15,16]$; (ii) the availability of a sequenced and fully annotated genome of high accuracy [19] (https://genome.jgi.doe.gov/Phlrad1/ Phlrad1.home.html); (iii) the availability of analyzed transcriptomes and proteomes following wood decomposition under aerobic conditions [4]. A fungal isolate was deposited in the Microbial Domain Biological Resource Centre HAMBI FBCC sub-collection (https://kotka .luomus.fi/culture/fbcc) of the Helsinki Institute of Life Science, University of Helsinki, Finland. The isolate was cultivated and maintained on malt extract agar $(2 \% \mathrm{w} / \mathrm{v})$ at $25^{\circ} \mathrm{C}$ in the dark throughout the study.

\section{Cultivation conditions}

Solid-state cultivations were performed in $100-\mathrm{mL}$ glass Erlenmeyer flasks that contained $4 \mathrm{~g}$ of dried spruce (Picea abies) wood as sawdust (particle size $\varnothing<2 \mathrm{~mm}$ ) mixed with $1 \mathrm{~g}$ of dried and milled core board $[15,30]$. The solid substrate mixture was dry autoclaved $\left(121{ }^{\circ} \mathrm{C}\right.$, $15 \mathrm{~min})$ prior to the addition of $20 \mathrm{~mL}$ of sterile $1 \%(\mathrm{w} / \mathrm{v})$ yeast extract solution, $\mathrm{pH} 3$. The yeast extract solution was prepared in water, and its acidity was adjusted with $\mathrm{HCl}$ prior to autoclaving $\left(121^{\circ} \mathrm{C}, 1 \mathrm{~atm}, 15 \mathrm{~min}\right)$. P. radiata was cultivated for 7 days on malt extract agar plates before a $6 \mathrm{~mm}$ fungal hyphae-agar plug was 
transferred into each flask (on top of the solid lignocelluloses). Cultivation flasks were sealed either with porous cellulose stoppers or with tight rubber plugs to create cultivation conditions with normal atmosphere or fermentative conditions, respectively. The atmosphere was analyzed by determining the proportions of $\mathrm{O}_{2}, \mathrm{CO}_{2}, \mathrm{~N}_{2}$, $\mathrm{CH}_{4}, \mathrm{C}_{2} \mathrm{H}_{4}$ and $\mathrm{N}_{2} \mathrm{O}$ in the culture flask gas phase with Agilent $7890 \mathrm{~B}$ gas chromatography equipped with thermal conductivity, flame ionization and electron capture detectors as previously reported [65]. The sample was obtained from the headspace of the cultivation vial with a syringe. The culture flasks were incubated without agitation at $25{ }^{\circ} \mathrm{C}$ in the dark, with three biological replicates. Samples were harvested from both atmospheric conditions on cultivation days 7,14 , and 21 . Liquid medium cultivations with monosaccharides, polygalacturonic acid, or apple pectin as the carbon source were performed similarly under both atmospheric conditions. The medium contained $1 \%$ yeast extract $\mathrm{pH} 3$ and $10 \mathrm{~g} / \mathrm{L}$ of either glucose, xylose, mannose, galactose, polygalacturonic acid, or pectin. Samples were collected by separating the culture liquid from the solid substrate and mycelium by vacuum suction through a glass microfiber filter. Filtered culture liquid was adopted for enzyme activity assays and extracellular metabolite analyses by HPLC.

\section{RNA-Seq and transcriptome assembling}

RNA was extracted and purified from mycelia growing in the solid lignocelluloses from three biological replicate cultures, under both atmospheric conditions, following previously described methods [4]. The yield of purified total RNA from "Spruce + board aerobic" cultivation was $183 \mu \mathrm{g}( \pm 65)$ and $46 \mu \mathrm{g}( \pm 6.4)$ from the cultivation "Spruce+board anaerobic". The six RNA samples were sequenced at BGI (Hong Kong, People's Republic of China). The quality trimmed RNA-Seq reads (number of reads varied between 22,944,957 and 23,415,252) of each sample were individually mapped against gene models of the genome assembly of $P$. radiata 79 [19] by STAR aligner version $2.4 .1 \mathrm{~b}$ as previously described [4].

\section{Transcriptome analyses}

Aligned reads of each RNA-Seq set were counted using the HTSeq package of Chipster software version 3.15 guided by an annotation file containing genomic coordinates of the gene models $[66,67]$. Differential gene expression between the transcriptomes was performed using DESeq 2 package [68] in the Chipster platform, as described previously [4]. Benjamini-Hochberg adjusted thresholds $p<0.05$ and log2-fold change $\geq 1$ or $\leq-1$ were used to determine significantly differentially expressed genes. Intracellular genes of core metabolism were analyzed by calculating fold change between cultivations 'spruce + board anaerobic' and 'spruce + board aerobic'. Previously obtained transcriptomes of $P$. radiata on solid spruce wood (five RNA-Seq sets) [4] and on malt extract liquid medium (three RNA-Seq sets) [4] were included in the differential expression analysis of CAZy genes, in order to compare different substrates and atmospheric conditions, and to reveal regulative features. Mfuzz clustering of the gene expression data was performed using the Mfuzz 2.42.0 packages [21] in $\mathrm{R}$ version 3.5.2 ( $\mathrm{R}$ Core Team 2019). Special attention was paid to annotated carbohydrate-active enzyme encoding genes (CAZy genes) of $P$. radiata $[4,19]$ along with the core metabolic genes annotated in this study. Hierarchical clustering and Venn diagrams were created using gplots 3.0.1.1 and Venn 1.7 packages, respectively, in $R(R$ Core Team 2019). For hierarchical and Mfuzz clustering, the read counts were transformed into variance stabilized transformation (VST) values with Chipster software [66].

\section{Promoter region analysis}

Promoter regions expanding $1000 \mathrm{bp}$ upstream of the start codon on all annotated genes of $P$. radiata 79 genome assembly were downloaded from the JGI MycoCosm portal (genome site: https://genome.jgi.doe.gov/ Phlrad1/Phlrad1.home.html). Enriched motifs within the promoter sequences were analyzed with the MEME Suite version 5.0.5 [69] package and MEME tool (meme-suite. org). The classic mode with default settings was used, apart from the occurrence being set to any number of repetitions', motif number set to 30 , and motif size set from 5 to $20 \mathrm{nt}$. The occurrence of known motifs such as sequences for binding of specific transcription factors was scanned with the MEME Suite FIMO tool [70].

\section{Enzyme activity assays}

Enzyme activity assays were performed in 96-well plate assay scale as previously described except for pectinase activity [71]. Pectinase activity was measured by using polygalacturonic acid as substrate and galacturonic acid as reference for product formation. Enzyme sample $(20 \mu \mathrm{l})$ and $60 \mu \mathrm{l}$ of substrate $(0.5 \%$ polygalacturonic acid $)$ were incubated for $10 \mathrm{~min}$ at $35{ }^{\circ} \mathrm{C}$. The reaction was seized by adding $100 \mu \mathrm{l}$ of dinitrosalicylic acid (DNS). The mixture was boiled for $5 \mathrm{~min}$ in a water bath, and the end product formation was measured at $540 \mathrm{~nm}$ with Spark multimode microplate reader (Tecan, Austria). Comparison of enzyme activities (mean values of three biological replicate values) was conducted with $t$ test in the R-environment. 


\section{Metabolic pathway prediction}

We functionally annotated all genes involved in core metabolism to reveal, which metabolic pathways were affected by the differential expression of genes within each transcriptome. We did so by using BLASTP searches with homologs from well-studied fungi such as the budding yeast S. cerevisiae, Basidiomycota species C. neoformans and species of the genus Aspergillus. Functional annotation was targeted into genes involved in glycolysis, pentose phosphate pathway, pectin metabolism, ergosterol synthesis, fatty acid and triglyceride syntheses, fatty acid $\beta$-oxidation, and glyoxylate shunt. The predicted translated $P$. radiata proteins representing phosphoketolase and acetyl kinase were inspected in detail with their nearest homologs adopting ClustalW, and the protein models were 3D structurally studied by homology modeling using Phyre2 web portal for protein modeling, prediction and analysis [72]. An HPLC method was used for the quantitation of extracellular metabolites such as ethanol, methanol, acetate, glycerol, galacturonate, xylose, galactose, mannose and glucose as previously described [16]. Illustrations of the metabolic pathways were generated by Pathway tools 23.0 [73].

\section{Supplementary information}

Supplementary information accompanies this paper at https://doi. org/10.1186/s13068-020-01677-0.

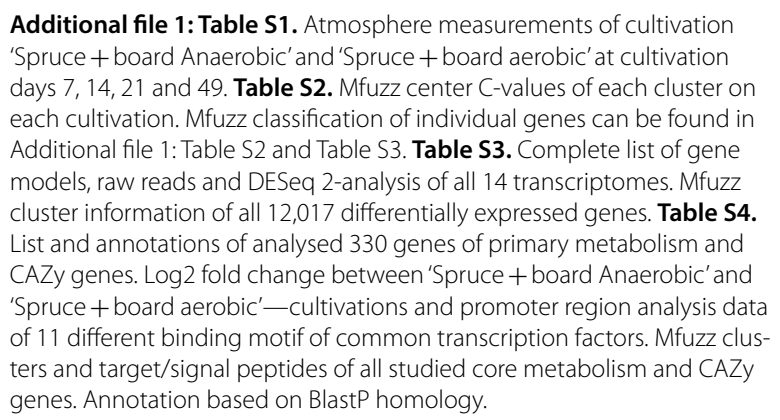

Additional file 2. Amino acid alignments of the translated protein candidates for phosphoketolase and acetyl kinase enzymes.

Additional file 3. $P$. radiata phosphoketolase $3 \mathrm{D}$ structure. File can be viewed e.g. at https://bioinformatics.org/firstglance/fgij/index.htm.

Additional file 4. Overlay of phosphoketolase 3D protein structures. Green $=$ P. radiata (plus.g11264), Gray = Bifidobacterium breve $3 \mathrm{AHC}$.

\footnotetext{
Abbreviations

CAZy: CAZyme carbohydrate-active enzyme; ROS: Reactive oxygen species; VST: Variance stabilizing transformation; LPMO: Lytic polysaccharide monooxygenase; LiP: Lignin peroxidase; MnP: Manganese peroxidase; SREBP: Stero regulatory element binding protein; TCA-cycle: Tricarboxylic acid cycle; PEP: Phosphoenol pyruvate; DHAP: Dihydroxyacetone phosphate; PPP: Pentose phosphate pathway.
}

\section{Acknowledgements}

Not applicable.

\section{Authors' contributions}

$\mathrm{HM}$ and TL conceived and designed the study. HM carried out fungal cultivations and HPLC analyses. HM and MM performed RNA extractions, RNA-Seq read and transcriptome analyses. HM produced clustering and promoter analyses, metabolic pathways, and figures and tables. HM and TL wrote the paper. All authors read and approved the final manuscript.

\section{Funding}

This work was supported by the Academy of Finland project (285676 to TL), Jane and Aatos Erkko foundation Grant (to TL), and Niemi foundation Grant (to HM). The funders had no role in study design, data collection and analysis, decision to publish, or preparation of the manuscript.

\section{Availability of data and materials}

The RNA-Seq data presented in this publication is deposited in NCBI's Gene Expression Omnibus and is accessible through GEO Series accession number GSE141153 (https://www.ncbi.nlm.nih.gov/geo/query/acc.cgi?acc=GSE14

1153). All other data generated or analyzed during this study are included in this published article and its additional information files.

\section{Ethics approval and consent to participate}

Not applicable.

\section{Consent for publication}

Not applicable.

\section{Competing interests}

The authors declare that they have no competing interests.

\section{Author details}

${ }^{1}$ Department of Microbiology, Faculty of Agriculture and Forestry, Viikki

Campus, University of Helsinki, 00014 Helsinki, Finland. ${ }^{2}$ Present Address: VTT

Technical Research Centre of Finland Ltd, 02044 VTT Espoo, Finland.

Received: 1 October 2019 Accepted: 5 February 2020

Published online: 24 February 2020

\section{References}

1. KirkTK, Farrell RL. Enzymatic "combustion": the microbial degradation of lignin. Microbiology. 1987;41:465-505. https://doi.org/10.1146/annur ev.mi.41.100187.002341.

2. Lundell TK, Mäkelä MR, de Vries RP, Hildén KS. Genomics, lifestyles and future prospects of wood-decay and litter-decomposing basidiomycota. Advances in botanical research. 1st ed. New York: Elsevier; 2014. https:// doi.org/10.1016/b978-0-12-397940-7.00011-2.

3. Hammel KE, Cullen D. Role of fungal peroxidases in biological ligninolysis. Curr Opin Plant Biol. 2008;11:349-55. https://doi.org/10.1016/j. pbi.2008.02.003.

4. Kuuskeri J, Häkkinen M, Laine P, Smolander O-P, Tamene F, Miettinen S, et al. Time-scale dynamics of proteome and transcriptome of the whiterot fungus Phlebia radiata: growth on spruce wood and decay effect on lignocellulose. Biotechnol Biofuels. 2016;9:192. https://doi.org/10.1186/ s13068-016-0608-9.

5. Presley GN, Schilling JS. Distinct growth and secretome strategies for two taxonomically divergent brown rot fungi. Appl Environ Microbiol. 2017:83:1-11. https://doi.org/10.1128/aem.02987-16.

6. Presley GN, Panisko E, Purvine SO, Schilling JS. Coupling secretomics with enzyme activities to compare the temporal processes of wood metabolism among white and brown rot fungi. Appl Environ Microbiol. 2018;84:e00159-218. https://doi.org/10.1128/AEM.00159-18.

7. Floudas D, Binder M, Riley R, Barry K, Blanchette RA, Henrissat B, et al. The Paleozoic origin of enzymatic lignin decomposition reconstructed from 31 fungal genomes. Science. 2012;336:1715-9. https://doi.org/10.1126/ science. 1221748

8. Binder M, Justo A, Riley R, Salamov A, Lopez-Giraldez F, Sjokvist E, et al. Phylogenetic and phylogenomic overview of the Polyporales. Mycologia. 2013;105:1350-73. https://doi.org/10.3852/13-003. 
9. Riley R, Salamov AA, Brown DW, Nagy LG, Floudas D, Held BW, et al. Extensive sampling of basidiomycete genomes demonstrates inadequacy of the white-rot/brown-rot paradigm for wood decay fungi. Proc Natl Acad Sci. 2014;111:9923-8. https://doi.org/10.1073/pnas.1400592111.

10. Eastwood DC, Floudas D, Binder M, Majcherczyk A, Schneider P, Aerts $A$, et al. The plant cell wall-decomposing machinery underlies the functional diversity of forest fungi. Science. 2011;333:762-5. https://doi. org/10.1126/science.1205411

11. Kamei I, Hirota Y, Mori T, Hirai H, Meguro S, Kondo R. Direct ethanol production from cellulosic materials by the hypersaline-tolerant white-rot fungus Phlebia sp. MG-60. Bioresour Technol. 2012;112:137-42. https:// doi.org/10.1016/j.biortech.2012.02.109.

12. Horisawa S, Inoue A, Yamanaka Y. Direct ethanol production from lignocellulosic materials by mixed culture of wood rot fungi Schizophyllum commune, Bjerkandera adusta, and Fomitopsis palustris. Fermentation. 2019;5:21. https://doi.org/10.3390/fermentation5010021.

13. Kozhevnikova EY, Petrova DA, Kopitsyn DS, Novikov AA, Shnyreva AV, Barkov AV, et al. New strains of Basidiomycetes that produce bioethanol from lignocellulose biomass. Appl Biochem Microbiol. 2016;52:638-42. https://doi.org/10.1134/s0003683816060090.

14. Kamei I, Hirota Y, Meguro S. Direct fungal production of ethanol from high-solids pulps by the ethanol-fermenting white-rot fungus Phlebia sp. MG-60. BioResources. 2014;9:5114-24.

15. Mattila H, Kuuskeri J, Lundell T. Single-step, single-organism bioethanol production and bioconversion of lignocellulose waste materials by phlebioid fungal species. Bioresour Technol. 2017;225:254-61. https://doi. org/10.1016/j.biortech.2016.11.082.

16. Mattila H, Kačar D, Mali T, Lundell T. Lignocellulose bioconversion to ethanol by a fungal single-step consolidated method tested with waste substrates and co-culture experiments. AIMS Energy. 2018;6:866-79. https://doi.org/10.3934/energy.2018.5.866.

17. Lombard V, Golaconda Ramulu H, Drula E, Coutinho PM, Henrissat B. The carbohydrate-active enzymes database (CAZy) in 2013. Nucleic Acids Res. 2014;42:D490-5. https://doi.org/10.1093/nar/gkt1178.

18. Kuuskeri J, Mäkelä MR, Isotalo J, Oksanen I, Lundell T. Lignocelluloseconverting enzyme activity profiles correlate with molecular systematics and phylogeny grouping in the incoherent genus Phlebia (Polyporales, Basidiomycota). BMC Microbiol. 2015;15:217. https://doi.org/10.1186/ s12866-015-0538-x.

19. Mäkinen M, Kuuskeri J, Laine P, Smolander O, Kovalchuk A, Zeng Z, et al. Genome description of Phlebia radiata 79 with comparative genomics analysis on lignocellulose decomposition machinery of phlebioid fungi. BMC Genomics. 2019;20:430. https://doi.org/10.1186/s12864-019-5817-8.

20. Edgar R, Domrachev M, Lash AE. Gene expression omnibus: NCBI gene expression and hybridization array data repository. Nucleic Acids Res. 2002;30:207-10. https://doi.org/10.1093/nar/30.1.207.

21. Futschik ME, Carlisle B. Noise-robust soft clustering of gene expression time-course data. J Bioinform Comput Biol. 2005;03:965-88. https://doi. org/10.1142/s0219720005001375.

22. Bissaro B, Várnai A, Røhr ÅK, Eijsink VGH. Oxidoreductases and reactive oxygen species in conversion of lignocellulosic biomass. Microbiol Mol Biol Rev. 2018;82:e00029-118. https://doi.org/10.1128/MMBR.00029-18.

23. Benocci T, Aguilar-Pontes MV, Zhou M, Seiboth B, De Vries RP. Regulators of plant biomass degradation in ascomycetous fungi. Biotechnol Biofuels. 2017;10:152. https://doi.org/10.1186/s13068-017-0841-x.

24. Aro N, IImén M, Saloheimo A, Penttilä M. ACEl of Trichoderma reesei is a repressor of cellulase and xylanase expression. Appl Environ Microbiol. 2003;69:56-65. https://doi.org/10.1128/AEM.69.1.56-65.2003.

25. Saloheimo A, Aro N, IImén M, Penttilä M. Isolation of the acel gene encoding a Cys2-His2 transcription factor involved in regulation of activity of the cellulase promoter cbh1 of Trichoderma reesei. J Biol Chem. 2000;275:5817-25. https://doi.org/10.1074/jbc.275.8.5817.

26. Häkkinen M, Valkonen MJ, Westerholm-Parvinen A, Aro N, Arvas M, Vitikainen $M$, et al. Screening of candidate regulators for cellulase and hemicellulase production in Trichoderma reesei and identification of a factor essential for cellulase production. Biotechnol Biofuels. 2014. https ://doi.org/10.1186/1754-6834-7-14.

27. Aro N, Saloheimo A, IImén M, Penttilä M. ACEIl, a novel transcriptional activator involved in regulation of cellulase and xylanase genes of Trichoderma reesei. J Biol Chem. 2001;276:24309-14. https://doi.org/10.1074/ jbc.M003624200.
28. Alazi E, Niu J, Kowalczyk JE, Peng M, Aguilar Pontes MV, van Kan JAL, et al. The transcriptional activator GaaR of Aspergillus niger is required for release and utilization of D-galacturonic acid from pectin. FEBS Lett. 2016;590:1804-15. https://doi.org/10.1002/1873-3468.12211.

29. Janusz G, Kucharzyk KH, Pawlik A, Staszczak M, Paszczynski AJ. Fungal laccase, manganese peroxidase and lignin peroxidase: gene expression and regulation. Enzyme Microb Technol. 2013;52:1-12. https://doi. org/10.1016/j.enzmictec.2012.10.003.

30. Mäkinen MA, Risulainen N, Mattila H, Lundell TK. Transcription of lignocellulose-decomposition associated genes, enzyme activities and production of ethanol upon bioconversion of waste substrate by Phlebia radiata. Appl Microbiol Biotechnol. 2018;102:5657-72. https://doi.org/10.1007/ s00253-018-9045-y.

31. Sjöström E. Wood chemistry fundamentals and applications. San Diego: Elsevier; 1993. https://doi.org/10.1016/c2009-0-03289-9.

32. Glenn K, Ingram-Smith C, Smith KS. Biochemical and kinetic characterization of xylulose 5-phosphate/fructose 6-phosphate phosphoketolase 2 (Xfp2) from Cryptococcus neoformans. Eukaryot Cell. 2014;13:657-63. https://doi.org/10.1128/ec.00055-14.

33. Thaker TM, Tanabe M, Fowler ML, Preininger AM, Ingram-Smith C, Smith KS, et al. Crystal structures of acetate kinases from the eukaryotic pathogens Entamoeba histolytica and Cryptococcus neoformans. J Struct Biol. 2013;181:185-9. https://doi.org/10.1016/j.jsb.2012.11.001.

34. Jung KW, Yang DH, Maeng S, Lee KT, So YS, Hong J, et al. Systematic functional profiling of transcription factor networks in Cryptococcus neoformans. Nat Commun. 2015;6:1-14. https://doi.org/10.1038/ncomm s7757.

35. Jung WH, Saikia S, Hu G, Wang J, Fung CKY, D'Souza C, et al. HapX positively and negatively regulates the transcriptional response to iron deprivation in Cryptococcus neoformans. PLoS Pathog. 2010;6:e1001209. https://doi.org/10.1371/journal.ppat.1001209.

36. Gancedo JM. Yeast carbon catabolite repression. Microbiol Mol Biol Rev. 1998;62:334-61. https://doi.org/10.1111/j.1432-1033.1992.tb16928.x.

37. Haurie V, Perrot M, Mini T, Jenö P, Sagliocco F, Boucherie H. The transcriptional activator Cat8p provides a major contribution to the reprogramming of carbon metabolism during the diauxic shift in Saccharomyces cerevisiae. J Biol Chem. 2001;276:76-85. https://doi.org/10.1074/jbc. M008752200.

38. Salazar M, Vongsangnak W, Panagiotou G, Andersen MR, Nielsen J. Uncovering transcriptional regulation of glycerol metabolism in Aspergilli through genome-wide gene expression data analysis. Mol Genet Genomics. 2009;282:571-86. https://doi.org/10.1007/s00438-009-0486-y.

39. Hughes AL, Todd BL, Espenshade PJ. SREBP pathway responds to sterols and functions as an oxygen sensor in fission yeast. Cell. 2005;120:831-42. https://doi.org/10.1016/j.cell.2005.01.012.

40. Nagy LG, Riley R, Tritt A, Adam C, Daum C, Floudas D, et al. Comparative genomics of early-diverging mushroom-forming fungi provides insights into the origins of lignocellulose decay capabilities. Mol Biol Evol. 2016;33:959-70. https://doi.org/10.1093/molbev/msv337.

41. Wang J, Suzuki T, Dohra H, Takigami S, Kako H, Soga A, et al. Analysis of ethanol fermentation mechanism of ethanol producing white-rot fungus Phlebia sp. MG-60 by RNA-seq. BMC Genomics. 2016;17:616. https://doi. org/10.1186/s12864-016-2977-7.

42. Henske JK, Springer SD, O'Malley MA, Butler A. Substrate-based differential expression analysis reveals control of biomass degrading enzymes in Pycnoporus cinnabarinus. Biochem Eng J. 2018;130:83-9. https://doi. org/10.1016/j.bej.2017.11.015.

43. Janusz G, Mazur A, Wielbo J, Koper P, Żebracki K, Pawlik A, et al. Comparative transcriptomic analysis of Cerrena unicolor revealed differential expression of genes engaged in degradation of various kinds of wood. Microbiol Res. 2018;207:256-68. https://doi.org/10.1016/j.micre s.2017.12.007.

44. Skyba O, Cullen D, Douglas CJ, Mansfield SD. Gene expression patterns of wood decay fungi Postia placenta and Phanerochaete chrysosporium are influenced by wood substrate composition during degradation. Appl Environ Microbiol. 2016;82:4387-400. https://doi.org/10.1128/aem.00134 $-16$.

45. Jurak E, Suzuki H, van Erven G, Gandier JA, Wong P, Chan K, et al. Dynamics of the Phanerochaete carnosa transcriptome during growth on aspen and spruce. BMC Genomics. 2018;19:815. https://doi.org/10.1186/s1286 4-018-5210-z. 
46. Yamakawa Y, Endo Y, Li N, Yoshizawa M, Aoyama M, Watanabe A, et al. Regulation of cellulolytic genes by McmA, the SRF-MADS box protein in Aspergillus nidulans. Biochem Biophys Res Commun. 2013;431:777-82. https://doi.org/10.1016/j.bbrc.2013.01.031

47. Alazi E, Knetsch T, Di Falco M, Reid ID, Arentshorst M, Visser J, et al. Inducer-independent production of pectinases in Aspergillus niger by overexpression of the D-galacturonic acid-responsive transcription factor gaaR. Appl Microbiol Biotechnol. 2018. https://doi.org/10.1007/s0025 3-018-8753-7.

48. Suparmin A, Kato T, Takemoto H, Park EY. Metabolic comparison of aerial and submerged mycelia formed in the liquid surface culture of Cordyceps militaris. Microbiologyopen. 2019;8:e836. https://doi.org/10.1002/ mbo3.836.

49. Pfeiffer T, Morley A. An evolutionary perspective on the Crabtree effect. Front Mol Biosci. 2014;1:1-6. https://doi.org/10.3389/fmolb.2014.00017.

50. De Deken $\mathrm{RH}$. The Crabtree effect: a regulatory system in yeast. J Gen Microbiol. 1966;44:149-56. https://doi.org/10.1099/00221287-44-2-149.

51. Adnan M, Zheng W, Islam W, Arif M, Abubakar Y, Wang Z, et al. Carbon catabolite repression in filamentous fungi. Int J Mol Sci. 2018;19:48. https ://doi.org/10.3390/ijms19010048.

52. Chang YC, Bien CM, Lee H, Espenshade PJ, Kwon-Chung KJ. Sre1p, a regulator of oxygen sensing and sterol homeostasis, is required for virulence in Cryptococcus neoformans. Mol Microbiol. 2007;64:614-29. https://doi. org/10.1111/j.1365-2958.2007.05676.x.

53. Burr R, Espenshade PJ. Oxygen-responsive transcriptional regulation of lipid homeostasis in fungi: implications for anti-fungal drug development. Semin Cell Dev Biol. 2018;81:110-20. https://doi.org/10.1016/j. semcdb.2017.08.043.

54. Larsson C, Påhlman IL, Ansell R, Rigoulet M, Adler L, Gustafsson L. The importance of the glycerol 3-phosphate shuttle during aerobic growth of Saccharomyces cerevisiae. Yeast. 1998;14:347-57. https://doi.org/10.1002/ (SICI)1097-0061(19980315)14:4\%3c347:AID-YEA226\%3e3.0.CO;2-9.

55. Zinser E, Paltauf F, Daum G. Sterol composition of yeast organelle membranes and subcellular distribution of enzymes involved in sterol metabolism. J Bacteriol. 1993;175:2853-8.

56. Young ET, Dombek KM, Tachibana C, Ideker T. Multiple pathways are coregulated by the protein kinase $\mathrm{Snf} 1$ and the transcription factors Adr1 and Cat8. J Biol Chem. 2003;278:26146-58. https://doi.org/10.1074/jbc. M301981200.

57. Turcotte $B$, Liang $X B$, Robert $F$, Soontorngun $N$. Transcriptional regulation of nonfermentable carbon utilization in budding yeast. FEMS Yeast Res. 2010;10:2-13. https://doi.org/10.1111/j.1567-1364.2009.00555.x.

58. Bekers KM, Heijnen JJ, van Gulik WM. Determination of the in vivo NAD:NADH ratio in Saccharomyces cerevisiae under anaerobic conditions, using alcohol dehydrogenase as sensor reaction. Yeast. 2015;32:541-57. https://doi.org/10.1002/yea.3078.

59. Ingram-Smith C, Martin SR, Smith KS. Acetate kinase: not just a bacterial enzyme. Trends Microbiol. 2006;14:249-53. https://doi.org/10.1016/j. tim.2006.04.001.

60. Chun CD, Liu OW, Madhani HD. A link between virulence and homeostatic responses to hypoxia during infection by the human fungal pathogen Cryptococcus neoformans. PLoS Pathog. 2007;3:e22. https://doi. org/10.1371/journal.ppat.0030022.
61. Mali T, Kuuskeri J, Shah F, Lundell TK. Interactions affect hyphal growth and enzyme profiles in combinations of coniferous wood-decaying fungi of Agaricomycetes. PLoS ONE. 2017;12:e0185171. https://doi. org/10.1371/journal.pone.0185171.

62. Bendjilali N, MacLeon S, Kalra G, Willis SD, Hossian AK, Avery E, et al. Timecourse analysis of gene expression during the Saccharomyces cerevisiae hypoxic response. G3 Genes Genomics Genet. 2017;7:221-31. https://doi. org/10.1534/g3.116.034991

63. Todd RB, Zhou M, Ohm RA, Leeggangers F, Visser L, de Vries RP. Prevalence of transcription factors in Ascomycete and Basidiomycete fungi. BMC Genomics. 2014;15:214. https://doi.org/10.1186/1471-2164-15-214.

64. Spatafora JW, Aime MC, Grigoriev IV, Martin F, Stajich JE, Blackwell M. The fungal tree of life: from molecular systematics to genome-scale phylogenies. Microbiol Spectr. 2017;5:1-32. https://doi.org/10.1128/microbiols pec.funk-0053-2016.

65. Penttilä A, Slade EM, Simojoki A, Riutta T, Minkkinen K, Roslin T. Quantifying beetle-mediated effects on gas fluxes from dung pats. PLOS ONE. 2013:8:e71454. https://doi.org/10.1371/journal.pone.0071454.

66. Kallio MA, Tuimala JT, Hupponen T, Klemelä P, Gentile M, Scheinin I, et al. Chipster: user-friendly analysis software for microarray and other high-throughput data. BMC Genomics. 2011;12:1. https://doi. org/10.1186/1471-2164-12-507.

67. Anders S, Pyl PT, Huber W. HTSeq-A Python framework to work with highthroughput sequencing data. Bioinformatics. 2015;31:166-9. https://doi. org/10.1093/bioinformatics/btu638.

68. Love MI, Huber W, Anders S. Moderated estimation of fold change and dispersion for RNA-seq data with DESeq2. Genome Biol. 2014;15:550. https://doi.org/10.1186/s13059-014-0550-8.

69. Bailey TL, Boden M, Buske FA, Frith M, Grant CE, Clementi L, et al. MEME Suite: tools for motif discovery and searching. Nucleic Acids Res. 2009;37:202-8. https://doi.org/10.1093/nar/gkp335.

70. Grant CE, Bailey TL, Noble WS. FIMO: scanning for occurrences of a given motif. Bioinformatics. 2011;27:1017-8. https://doi.org/10.1093/bioinforma tics/btr064.

71. Rytioja J, Hildén K, Hatakka A, Mäkelä MR. Transcriptional analysis of selected cellulose-acting enzymes encoding genes of the white-rot fungus Dichomitus squalens on spruce wood and microcrystalline cellulose. Fungal Genet Biol. 2014;72:91-8. https://doi.org/10.1016/j. fgb.2013.12.008.

72. Kelley LA, Mezulis S, Yates CM, Wass MN, Sternberg MJE. The Phyre2 web portal for protein modeling, prediction and analysis. Nat Protoc. 2016;10:845-58. https://doi.org/10.1038/nprot.2015-053.

73. Paley S, O'Maille PE, Weaver D, Karp PD. Pathway collages: personalized multi-pathway diagrams. BMC Bioinform. 2016;17:1-10. https://doi. org/10.1186/s12859-016-1382-1.

\section{Publisher's Note}

Springer Nature remains neutral with regard to jurisdictional claims in published maps and institutional affiliations.

Ready to submit your research? Choose BMC and benefit from

- fast, convenient online submission

- thorough peer review by experienced researchers in your field

- rapid publication on acceptance

- support for research data, including large and complex data types

- gold Open Access which fosters wider collaboration and increased citations

- maximum visibility for your research: over $100 \mathrm{M}$ website views per year

At BMC, research is always in progress.

Learn more biomedcentral.com/submissions 